\title{
Uma Relação Possível entre os Inclassificáveis e a Modernidade Líquida
}

\author{
A Possible Relationship between the Unclassifiable and Liquid Modernity \\ Una Posible Relación entre los Inclassificables y la Modernidad Neta
}

\author{
Talita Noronha Alves
}

Juliana Fonsêca de Almeida Gama

Universidade Estadual da Paraíba (UEPB), Campina Grande, PB, Brasil

\section{Resumo}

A psicanálise muito se ocupou de compreender as sociedades e sujeitos que a compõem, e, disto, Freud desenvolveu as três estruturas clínicas. Contudo, foi com Lacan que a psicose foi mais explorada teórica e clinicamente. Depois, com Miller e a "formalização" do termo "psicose ordinária", em 1998, há também os "inclassificáveis", que escapam destas estruturas. Na sociologia, Bauman cria o termo "Modernidade Líquida", para se referir a este tempo de desbussolamento do sujeito, de escape e perda de referencial, que nos motivou a discutir, teoricamente, quais as relações entre essa modernidade e as estruturas psíquicas existentes e reconhecidas pela psicanálise Freud-lacaniana. Tal discussão foi realizada através de revisão bibliográfica das obras de Freud, Lacan, Miller e Bauman, resultando no entendimento de que as formas de gozo se multiplicaram e seu valor simbólico para o sujeito se estilhaçou; aquilo que era a regra, hoje é mais um dos desvios dos sintomas.

Palavras-Chave: Psicanálise; Psicose Ordinária; Modernidade Líquida.

\begin{abstract}
Psychoanalysis was very concerned with understanding the societies and subjects that compose it, and, from this, Freud developed the three clinical structures. However, However, with Lacan psychosis started to be more explored theoretically and clinically. Then, with Miller and the "formalization" of the term "ordinary psychosis", in 1998, there are also the "unclassifiable", who escape these structures. In sociology, Bauman coined the term "Liquid Modernity", to refer to this time of subject disbussing, of escape and loss of reference, which motivated us to discuss, theoretically, which relationships are between this modernity and the existing psychic structures and recognized by Freud-Lacanian psychoanalysis. Carried out through a bibliographic review from Freud, Lacan, Miller and Bauman's work, which results in the, resulting in the understanding that the forms of jouissance multiplied and their symbolic value for the subject shattered; what used to be the rule, today is yet another symptom deviation.
\end{abstract}

Keywords: Psychoanalysis; Ordinary Psychosis; Liquid Modernity. 


\section{Resumen}

El psicoanálisis se preocupó mucho por comprender las sociedades y los sujetos que lo componen y, a partir de ello, Freud desarrolló las tres estructuras clínicas. Sin embargo, fue con Lacan que la psicosis se exploró más teórica y clínicamente. Luego, con Miller y la "formalización" del término "psicosis ordinaria", en 1998, también están los "inclasificables", que escapan a estas estructuras. En sociología, Bauman acuñó el término "Modernidad líquida", para referirse a este tiempo de discusión de sujetos, de escape y pérdida de referencia, que nos motivó a discutir, teóricamente, cuáles son las relaciones entre esta modernidad y las estructuras psíquicas existentes y reconocido por el psicoanálisis freudlacaniano. Dicha discusión se llevó a cabo mediante una revisión bibliográfica de las obras de Freud, Lacan, Miller y Bauman, dando como resultado la comprensión de que las formas de goce se multiplicaron y su valor simbólico para el sujeto se hizo añicos; lo que solía ser la regla, hoy es otra desviación de síntoma.

Palabras clave: Psicoanálisis; Psicosis Ordinária; Modernidad Líquida.

\section{Introdução}

Associar psicanálise e sociologia não é fato novo na história dessas duas ciências humanas. Muitos já o fizeram, muitos ainda o farão. Isto porque há muita riqueza na associação entre o objeto de estudo da psicanálise - o inconsciente -, e aquilo que a sociologia tem como objeto as sociedades e suas relações -, justo no ponto em que o inconsciente rege os sujeitos e os sujeitos formam as sociedades.

Sigmund Freud, criador da psicanálise, descobriu o inconsciente e o inventou como objeto de interesse ao trabalho psicanalítico, tal qual o conhecemos hoje. A partir de sua formação, pôde estudar a histeria considerando outras possibilidades, que não só as orgânicas, para a etiologia dos males "dos nervos" que eram clinicamente "invisíveis", mas geravam sintomas situados no real do corpo. Daí nasce a psicanálise enquanto teoria.

Com a psicanálise em andamento, anos mais tarde, Jacques Lacan, se dispôs a não recuar diante das psicoses, tal qual como fizera Freud, segundo Riolfi (2014). De início, fez uma releitura das obras freudianas, pois considerava que o original já havia sido distorcido por seus sucessores. Munido de vasto conhecimento sobre os campos da linguística de Saussure e do estruturalismo de Lévi-Strauss, bem como da matemática, Lacan introduziu conceitos importantes à clínica psicanalítica, como a de que “o inconsciente é, em seu fundo, estruturado, tramado, encadeado, tecido de linguagem" 
(Lacan,1985, p. 139), e, um dos mais importantes, o conceito de sinthoma.

Lacan propôs, a priori, uma clínica estruturalista, conhecida como "Primeira clínica". Nesta, apresentou avanços com base nas estruturas fundamentais freudianas derivadas do Complexo deÉdipo, quais sejam: neurose, psicose e perversão; realizando, principalmente, uma reinterpretação deste complexo.Não somente, apresentou e desenvolveu o conceito dos três registros- Imaginário, Simbólico e Real-debruçando-se sobre o caso Schreber e avançando na ideia de imprescindibilidade do Nome-do-Pai como significante universal, tornando-o apenas uma metáfora.

$\mathrm{Na}$ "Segunda clínica", conhecida como "Clínica dos nós", Lacan comentou a obra de James Joyce e apresentou a psicose através da topologia dos nós borromeanos, articulados aos registros do Imaginário, Simbólico e Real. Contudo, foi com Jacques-Alain Miller que o estruturalismo de Freud começou a ser expandido, a despeito da possibilidade de um outro tipo de constituição estrutural possível: os inclassificáveis.

Esta nova possibilidade de arranjo estrutural, a priori denominada de "casos raros", foram amplamente discutidas em três momentos: o Conciliábulo de Angers, em 1996; a Conversação de Arcachon, em 1997; e a Convenção de Antibes, em 1998. Em todos estes encontros, muitas foram as tentativas de nomear os casos raros apresentados, enquadrando-os em uma das três estruturas já conhecidas, mas com algum indicativo de que estariam no campo da psicose. Contudo, nenhuma das tentativas de nomeação destes casos parecia conveniente ou capaz de dar conta da amplitude do enigma. Segundo Tironi (2010), é a partir destes casos que se amplia a possibilidade de que haja psicoses - no plural -, no sentido de que há um outro tipo de psicose, que não a já conhecida psicose extraordinária, na qual os fenômenos elementares são bem definidos.

Então, apenas em 1998, na Convenção de Antibes, se define algum consenso, concluindo que tais casos pertencem, definitivamente, ao campo da psicose, salvaguardando um elemento essencial que a difere da psicose extraordinária, que é o não desencadeamento psicótico. A partir desta discussão, Miller utiliza pela primeira vez o termo "psicose ordinária", com o que parece ser o termo mais próximo do que trata esta psicose, que tem uma forma de apresentação mais branda e sutil. Apesar disso, e considerando que muito sobre estas novas formas de psicose ainda está se 
pondo para a psicanálise, utiliza-se o termo “inclassificável” como mais indicado, por sua neutralidade diante das estruturas freudianas.

Essas novas formas de psicose, na segunda clínica de Lacan, aludem à descoberta de que o Nome-do-Pai não é o significante universal, tal como se pensava.Há algo na configuração e na sustentação das estruturas psíquicas que se diferencia das formas de negação da castração pensadas em torno de um significante fálico. A partir do caso de James Joyce, então, Lacan construiu uma nova forma de amarração dos três registros (RSI) que não passa, obrigatoriamente, pela noção de Nome-do-Pai como sendo $\mathrm{O}$ sintoma primordial, e, disto, concluiu que o Nome-do-Pai é apenas mais uma dentre tantas formas de amarrações e suplências possíveis ao sujeito.

Desde o desenvolvimento da teoria, a psicanálise freudiana estabeleceu estreita relação com o social, a exemplo das pacientes histéricas, cuja somatização e sintomatologia eram produto da cultura da época. A partir do século XX, quando a maioria dos grandes fenômenos históricos ocorreram, a psicanálise entrou como ferramenta de crítica a tudo quanto já havia se estabelecido na sociedade, nas ciências, no conhecimento e, principalmente, na cultura. Há uma liquefação dos sistemas de modo geral: antes sólidos, fixos, normatizados; passam a ser mais fluidos, líquidos e dinâmicos.

É a partir deste desmoronamento do sólido, que o uso do termo "líquido"se impõe para nomear a dinâmica de relações para Zygmunt Bauman, que cunha o termo "Modernidade Líquida" (2001) para se referir e se contrapor ao termo mais utilizado, hoje, para aludir à nossa configuração social: a pós-modernidade.

Dito isto, é no curso do desenvolvimento da psicanálise ao longo do século XX e XXI que se estabelece a ponte entre a psicanálise e a sociologia, conquanto ambas as ciências, por vezes, se complementam quando compreendem e se debruçam sobre a dinamicidade das relações sociais, humanas e culturais. Tal ideia se sustenta quando se compreende que é a partir da coisa social que os indivíduos se organizam como sujeitos, na produção de seus sintomas e na reverberação desta estruturação do sujeito no ser social, cujo produto é a sociedade persi.

Assim, e partindo da prerrogativa de que passamos por um período característico desta nova forma de configuração da sociedade líquida, fora-dalei, sem modelos, sem proibições e com 
muitas ofertas, objetivou-se, neste trabalho, discutir qual(is) a(s) relação(ões) entre o tempo, aqui denominado "Modernidade Líquida", e as estruturas psíquicas existentes e reconhecidas pela psicanálise Freud-Lacaniana. Com vistas ao alcance deste objetivo, buscou-se investigar as construções de Freud e Lacan com relação às estruturas psíquicas, compreendendo os lugares ocupados por estas, sobretudo o lugar das psicoses, ao longo da primeira e da segunda clínica lacaniana; bem como diferenciar a psicose ordinária, na história da psicanálise, como uma configuração psíquica recémabordada (1998) e refletir sobre o efeito do tempo nos olhares lançados às estruturas psíquicas.

Para tanto, e para alcançar estes objetivos, foram utilizados como bibliografia básica da psicanálise, textos de Freud, Lacan e Miller. Sobre Freud, foram considerados, sobretudo, "A dissolução do complexo de Édipo" (2011 [1924]) e "Algumas consequências psíquicas da diferença anatômica entre os sexos" (2011 [1925]). Em Lacan, as referências primordiais foram o "Seminário 3: As psicoses" (1955-1956) e o "Seminário 5: A formações do Inconsciente” (1957-1958). E em Miller, essencialmente, a obra “A psicose ordinária: a Convenção de
Antibes" (2012). No que compete à sociologia, foram tomadas como base duas obras de Zygmunt Bauman, quais sejam: "Modernidade Líquida" (2001) e “O retorno do pêndulo: sobre a psicanálise e o futuro do mundo líquido" (2017).

\section{A clínica psicanalítica: de Freud à}

Lacan

É indispensável, ao se propor tratar da clínica lacaniana, traçar, primeiramente, um percurso que perpassa brevemente por Freud e sua clínica estrutural.Como se sabe, Sigmund Freud, neurologista, nascido em Viena em 1865, criou a psicanálise como resultado da evolução de seus estudos com pacientes doentes dos nervos. Por sua expertise no sistema nervoso, ganhou notoriedade e uma bolsa para estudar com Charcot, na Salpetrierre, em Paris, onde teve seu primeiro contato com o que até hoje é chamado de histeria (Freud, 2011).

De volta à Viena, Freud tratou clinicamente pacientes neuróticos através de dois métodos, a saber, a eletroterapia e a hipnose. Entretanto, ao longo do percurso, optou por abandoná-los ao constatar que o primeiro era raso e ineficaz, e que o segundo não era aplicável a todos os pacientes. Foi no curso do tratamento de 
uma paciente de Josef Breuer, nomeada Ana O., que Freud descobriu o "método catártico" que consistia na "cura pela fala" (Freud, 2011, p. 53). Em seguida, com outra paciente, descobriu o que chamou de regra fundamental da psicanalise: a associação livre (Freud, 2016).

No curso dos seus estudos com as histéricas, Freud e Breuer dissidiram quanto à etiologia da histeria. Freud considerava que os conteúdos represados, que culminavam nos sintomas histéricos, comunicavam desejos reprimidos relacionados a conteúdos de origem sexual na qualidade de traumas (Freud, 2016).É a partir do contato com esse padrão etiológico da histeria que Freud se debruça no entendimento da sexualidade humana e desenvolve a teoria das fases psicossexuais infantis. Disto, o Complexo de Édipo torna-se ponto basal em sua clínica, uma vez que, deste complexo, adviria a formação estrutural psíquica.Esta formação estrutural, por sua vez, divide-se em neurose, psicose e perversão; e é ao estudo da neurose que Freud mais se dedica. Sobre a psicose e a perversão pouco se detém, sobretudo por considerar, àquela época, o recurso da psicanálise contraindicado aos sujeitos psicóticos (Freud,1976).
Diante desta querela sobre os sujeitos psicóticos então, é que Jacques Lacan se dispõe a seguir frente ao desafio de uma clínica, começando de uma releitura das obras de Freud, donde pôde desenvolver para além da psicose. Devido a isto, a primeira clínica de Lacan é também estruturalista, tal como a originária, freudiana; salvaguardando alguns questionamentos próprios, no que tangem o Complexo de Édipo e a função paterna, que Lacan reduz ao status de metáfora paterna (Lacan, 1999).

Ao dizer que "o pai é uma metáfora” (Lacan,1999, p. 180) Lacan quer dizer que "a função do pai no complexo de Édipo é ser um significante que substitui o primeiro significante introduzido na simbolização - o significante materno" (Lacan, 1999, p. 180). É o que o pai tem o falo - que promove as idas e vindas da mãe, que agora dirige sua atenção, antes exclusiva ao bebê, para outro objeto de seu desejo. Esse outro desejo da mãe, que a leva a ir embora e que a traz de volta, é o falo.

Quando se fala no pai como metáfora, é também porque este é simbólico e significante. Em Freud, o pai da horda primeva era simbólico, porque foi posto, culturalmente, nesta posição. Esse pai não era situado no Real, ainda que sua 
influência se estabelecesse no plano da realidade (Freud, 2012). Lacan diz, sobre a metáfora paterna, que o pai só existe como Nome-do-Pai, porque the foi conferido um lugar simbólico, cultural e social; como reprodutor, como parte presente para a elaboração de um filho - e é a mãe que ratifica este lugar (Lacan, 1999).

Para Lacan, Freud dá demasiada ênfase ao Complexo de Édipo e ao que ocorre depois dele, sem considerar a vital importância do que o precede. Deste período pré-edipiano, Lacan (1999, p. 168) diz que "Algumas partes de nosso campo de experiência relacionam-se, especialmente, com esse campo das etapas pré-edipianas do desenvolvimento do sujeito, quais sejam, a perversão, de um lado, e a psicose, de outro".Embora discorde de Freud em alguns aspectos, Lacan converge com sua teoria quando diz que "o complexo de Édipo tem uma função normativa, não simplesmente na estrutura moral do sujeito, nem em suas relações com a realidade, mas quanto à assunção de seu sexo" (1999, pp. 170-171).

Neste ponto, Lacan problematiza sobre a função paterna para o complexo de Édipo, no sentido de questionar se um pai muito presente é melhor ou pior que um pai ausente; e mesmo se o pai é realmente necessário para que haja o Édipo. Quanto a isto, Lacan (1999, p. 173) diz que: "é perfeitamente possível, concebível, exequível, palpável pela experiência, que o pai esteja presente mesmo quando não está", o que corrobora com a elevação da figura paterna ao status de Deus-pai, como em “Totem e Tabu" (Freud, (2012), no qual o assassinato do pai tirânico pelos filhos não os liberta deste, mas, pelo contrário, torna sua presença ainda mais poderosa.

Outro ponto de concordância entre Lacan e Freud é que ambos apontam a função paterna como parte fundamental no Édipo, por quanto interditora do incesto entre a mãe e o filho. Por estar presente a interdição, há também a castração no Édipo reeditado por Lacan. Tomando por referência o menino, para Lacan, é a intensidade do medo de ser castrado pelo pai, por desejar a mãe, que exerce maior impacto na estruturação do sujeito (Lacan, 1999).

Essa ameaça de castração em Freud e Lacan também funciona de forma semelhante. Contudo, Lacan, dividindo o Édipo em três tempos, descreve a ameaça de castração em três estratos e etapas. No primeiro tempo edipiano, a criança quer continuar sendo, tal como imagina, o único objeto de desejo da mãe. Todavia, ao perceber que a mãe se volta para um 
Outro, a criança quer ser tal qual esse Outro, para que também possa ser amado.Neste momento, advém o pai real, no sentido da realidade, sob uma presença ainda velada (metáfora paterna). Essa mãe, apesar disso, atuando como mãe, mas também como mulher desejante, instaura, na forma de significante, o Nome-do-Pai, dando sentido ao seu desejo pelo que lhe falta.Disto, a metáfora paterna já está introduzida enquanto símbolo do discurso e da Lei.

No segundo tempo, o pai, outrora apenas anunciado, intervém como privador da mãe, do falo simbólico, e também do incesto, atuando como Lei. Em referência a este segundo tempo, Lacan (1999, p. 199) explica mais resumidamente da seguinte forma:

A estreita ligação desse remeter a mãe a uma lei que não é a dela, mas a de um Outro, com o fato de o objeto de seu desejo ser soberanamente possuído, na realidade, por esse mesmo Outro a cuja lei ela remete, fornece a chave da relação do Édipo.

Neste tempo, vem à tona, portanto, o pai Imaginário, como a criança consegue representar a partir do discurso que a mãe porta e ratifica. Diante dessa Lei, a criança confere ao pai o poder da possibilidade de sua castração, mas percebe que nem o pai é aquilo que a mãe deseja, mas que ele é, antes, possuidor do que a mãe deseja. $\mathrm{O}$ pai, portanto, tem o objeto de desejo da mãe. A partir deste ponto, a questão central da criança não é mais ser, e sim, ter aquilo que ele vê que o pai tem e que a mãe deseja.

Com o terceiro tempo, surge o pai Real, que se revela como aquele que tem o falo e que, enquanto agente de uma castração simbólica, unifica o desejo e a Lei, levando ao declínio do Complexo de Édipo (Julien, 2003). Neste terceiro e último tempo, que remete à saída do complexo, o pai se firma como possuidor do falo, daquele que o dá ou o tira da mãe conforme sua vontade.Segundo Lacan (1999, p. 200):

É por intervir no terceiro tempo como aquele que tem o falo, e não que o é, que se pode produzir a báscula que reinstaura a instância do falo como objeto desejado pela mãe, e não mais apenas como objeto do qual o pai pode privar.

Nesse sentido, o filho percebe que a mãe não é um sujeito desejante, mas um 
sujeito objeto. Daí, elucubra-se o ponto crucial que Lacan desenvolve e que falta em Freud, e que é a ideia de que a privação no complexo de Édipo é também da mãe, e não da criança apenas.

Quanto aos níveis da ameaça de castração, Lacan propõe que, no primeiro nível, ao manipular o pênis e ser proibido pela mãe de fazê-lo, o menino sente no Imaginário a ameaça de ser castrado por alguém real (R.i). No segundo nível, o pai frustra o filho da posse da mãe, pois o pai como Simbólico age sobre um objeto real, que é a mãe (S'.r). No terceiro e último nível, o pai se faz preferir em função da

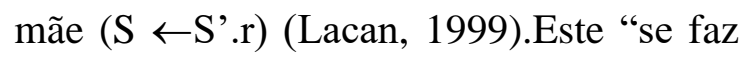
preferir em relação à mãe" se traduz no amor que o menino e a menina têm pelo pai, corroborando com a teoria freudiana. Assim como em Freud, esse amor pelo pai -do menino um amor de admiração, da menina um amor de querer-ter o que o pai tem, ou querer-ser o objeto de amor do pai - se configurariam, em outras palavras, na formação do Ideal do eu (Lacan, 1999).

Neurose, psicose ou perversão? - A clínica estrutural dos diagnósticos e sua relação com o complexo de édipo

Se é a partir do Édipo que o sujeito negocia sua adesão à conjunção do desejo e da falta, isto quer dizer também que é a partir de sua passagem pelo complexo, a priori, que sua fixação em uma estrutura se dará, de modo que a forma como cada um passa por este momento do desenvolvimento e da constituição psíquica terá forte influência no diagnóstico estrutural; diagnóstico este que, num sentido restrito (Quinet, 1991), para o analista, menos que para uma classificação, serve como norte à construção e condução do tratamento.

Assim, e orientando-se pela psicanalise lacaniana, na neurose o sujeito atravessa as três fases do Édipo, admite sua castração e ratifica a Lei instaurada, submetendo-se à interdição da satisfação do seu desejo pelo desejo do Outro, o que gera sofrimento e angústia constantes, como sintomas de sua castração. Na neurose, "a estrutura edipiana se presentifica no sintoma" que "fornece um acesso à organização simbólica que representa o sujeito" (Quinet, 1991, p. 20), de modo que o conteúdo edipiano que foi recalcado retorna no registro Simbólico sob a forma de sintoma.

Na perversão, o sujeito não admite o interdito do pai sobre o incesto, e não o aceita de modo que, desta forma, não constitui solidamente o Supereu, produto do Complexo de Édipo. O sujeito de 
estrutura perversa, então, admite, e, concomitantemente, recusa a castração no Simbólico, desmentindo-a. Assim, o que foi desmentido retorna também no registro do Simbólico conservado sob a forma de fetiche (Quinet,1991).

Por fim, o sujeito de estrutura psicótica fixa-se à primeira fase do Édipo; fase em que permanece colado ao desejo da mãe, como objeto.Essa não separação simbiótica ao desejo da mãe se dará pela não introdução deste terceiro pelo sujeito materno - o pai - e, portanto, da Lei que ele portaria, fazendo com que o sujeito mantenha o pai simbólico, zerificado, velado, sempre fora, porque ele nunca entra (foraclusão do Nome-do-Pai) (Quinet, 1991).

Nesse campo dos diagnósticos, então, e em que pese $\mathrm{o}$ respeito às singularidades dos sujeitos, deve-se também considerar aqueles sujeitos que não se alinham a nenhuma das três estruturas clássicas conhecidas até agora: os inclassificáveis.

\section{Os inclassificáveis}

Como visto nos tópicos anteriores, o estudo da psicose foi um dos diferenciais entre as clínicas psicanalíticas de Freud e Lacan. Entretanto, a psicose ordinária, especificamente, foi uma descoberta de Lacan e Jacques-Alain Miller, sendo este último o responsável por cunhar o termo “psicose ordinária” (Tironi, 2010, p. 1), em 1998, na Convenção de Antibes.

Foi através do caso de James Joyce que uma clínica diferencial das psicoses foi necessária, uma vez que o saber reunido até então não explicava satisfatoriamente este caso sob o qual Lacan se debruçou. Havia, então, um novo ato em cena: a psicose ordinária - os inclassificáveis das categorias Freud-Lacanianas.

Considerava-se, a priori, que estes inclassificáveis eram casos raros, pouco frequentes. No entanto, ao longo das três conversações clínicas realizadas, notou-se que havia uma frequência menos que rara destes casos, a saber: "os casos raros que escapavam as normas clássicas da clínica lacaniana da psicose eram mais frequentes do que inicialmente se supunha e, impossíveis à classificação, indicavam um mais além da perspectiva estritamente estruturalista" (Tironi, 2010, p. 1).

Mesmo antes de Miller oficializar o termo da psicose ordinária em 1998, Lacan, em 1955-1956, no "Seminário 3", ensaia o termo "pré-psicose" (Brodksy, 2011, p. 23) ao tratar sobre as psicoses não desencadeadas, mas que continham estranhezas próprias desta estrutura; no 
entanto, deixa o termo de lado, segundo Brodsky (2011, p. 23), quando parece perceber que "tornou-se insuficiente para dar conta do que pretendia abordar", o que já mostrava a dificuldade de nomeação de algo tão singular.

Qual seria, então, a melhor forma de definir a psicose ordinária a nível de termo? Como defini-la, a nível de estrutura ou outra coisa? Segundo Miller (2005, p. 400): "Toda classificação bem feita deve incluir a classe dos inclassificáveis". Se há uma suplência ou um sinthoma que amarra a estrutura do sujeito, este pode vir a nunca se desestabilizar gravemente, daí a dificuldade de avolumamento da literatura sobre a psicose ordinária. Seria a pósmodernidade e o crescente declínio do Nome-do-Pai uma das causas para o maior número de psicoses não desencadeadas? Até que ponto essas suplências dos sujeitos são motivo de entusiasmo em que pese menos ocorrências de sujeitos em surtos psicóticos?

Lacan (1955-1956, p. 231, citado por Brodsky,2011, p. 26), utiliza-se tanto dos três registros - Real, Simbólico e Imaginário (RSI) -quanto da clínica borromeana na explicação do que se sucede na clínica da psicose ordinária, a saber:
Nem todos os tamboretes tem quatro pés. Há os que ficam em pé com três. Contudo, não há como pensar que venha a faltar mais um só senão a coisa vai mal. (...) É possível que de saída não haja no tamborete pés suficientes, mas que ele fique firme assim mesmo até certo momento, quando o sujeito, numa encruzilhada de sua história biográfica, é confrontado com esse defeito que existe desde sempre.

Corroborando com o dito de Lacan, a autora ainda acrescenta que: "O que chamamos de psicose ordinária é uma psicose que consegue uma amarração tão estável como a da neurose, mas sem o Nome-do-Pai" (Brodsky, 2011, p. 48), reforçando o que Lacan chama de "clínica das suplências" no "Seminário 3" (Brodsky, 2011, p. 4). Para Miller (Brodsky, 2011), a psicose ordinária seria, então, uma questão de intensidade dentro do próprio campo da psicose, e não de outra estrutura para além das três existentes, e menos ainda de uma estrutura limítrofe entre a neurose e a psicose extraordinária.

Para Brousse (2009), em seu texto “A Psicose Ordinária à luz da teoria lacaniana dos discursos", a psicose 
ordinária, trata-se, ainda, de um trabalho em progresso, como se pode perceber na multiplicidade de definições e conceituações até hoje discutidas. Destarte, o que é fato é que, no caso das psicoses ordinárias, há uma questão latente quanto às formas de enodamento e desenodamento dos registros RSI.

Quanto às dessemelhanças entre a psicose extraordinária e a psicose ordinária, estas são muito tênues. Tênues porquanto estejam na mesma estrutura (a psicose) e por apresentarem os mesmos fenômenos, sendo que, na psicose ordinária estes tendem a se apresentar de forma mais sutil e branda, justo porque uma das maiores diferenciações entre a psicose extra e ordinária é o desencadeamento, ou seja, o surto psicótico. No surto, o sujeito perde o contato com a realidade quando convocado diante de um significante que lhe é enigmático, fruto da alienação ao Outro materno.

Essa perda do contato com a realidade, em forma de re-equilibração (Freud, 2010) se dá de forma que o psicótico em surto cria sua própria realidade alternativa para tentar preencher aquele buraco com o qual esteve sempre na borda, mas desta vez caiu - buraco este representado pelo objeto a, substituinte do
Nome-do-Pai na segunda clínica de Lacan. O diferencial mesmo da psicose ordinária é a estabilização banal, porque possível ao sujeito, que tende a encontrar sozinho sua própria amarração. De acordo com Mazzotti (2009, p. 83, citado por Correia, 2010, p. 4):

A Psicose ordinária tem, a
princípio, uma conotação simples,
fundado no fenômeno clínico:
ordinária é o contrário de
extraordinária. Não se veem
alucinações, fenômenos
elementares significativos, nem um
delírio articulado. (...) Estamos, ao
contrário, em presença do que,
intensamente, confunde-se com o
que não é psicose (...) um
desequilíbrio consequente de uma
contingência aparentemente banal,
revela-se precisamente uma
psicose.

Desde a segunda clínica de Lacan, torna-se necessário considerar múltiplas formas de apresentação da psicose, dadas as diferentes formas de amarração dos três registros (RSI) que não mais dependem exclusivamente do Nome-do-Pai. Agora se fala em psicoses, no plural. Assume-se, portanto, que as classificações 
estruturalistas vigentes até então, deveriam ser consideradas como semblantes, ou seja, aquilo que "consiste em fazer crer que há algo ali onde não há” (Miller, 2001, p. 18).

\section{Os inclassificáveis como fruto da pós- modernidade}

A utilização do termo "liquidez" como conceito adjetivo da modernidade é um atributo do sociólogo polonês Zygmunt Bauman, que se utiliza deste termo para caracterizar a atual configuração social, denominada por alguns de "pósmodernidade" (Bauman, 2001, p. 34) ou "hipermodernidade" e, por fim, cujos significados retornam a um denominador comum, que é tratar da sociedade contemporânea.

Segundo Bauman, que prefere chamar nossa sociedade atual de "sociedade da modernidade fluida" (2001, p. 34), ou apenas modernidade líquida, a utilização do termo "liquidez" se justifica porque "os líquidos, diferentemente dos sólidos, não mantêm sua forma com facilidade. Os fluídos, por assim dizer, não fixam o espaço nem prendem o tempo" (2001, p. 8).

Essa escolha de termo do sociólogo se dá para efeito de comparação às sociedades que ele denomina de "sólidas", pretéritas ao século XX, cuja direção era a modernização, apósa consolidação do capitalismo, e cuja mudança de estado da "solidez" de outrora para a "liquidez" atual se configuraria na liquefação das "lealdades tradicionais, dos direitos costumeiros e das obrigações que atavam pés e mãos” (Bauman, 2001, p. 10).

Essa transmutação do sólido em líquido é exemplificada por Clauss Offe (1987, citado por Bauman, 2001, p. 11), em sua obra "A utopia da opção zero" quando diz que as sociedades

$$
\begin{aligned}
& \text { complexas se tornaram rígidas a tal } \\
& \text { ponto que a própria tentativa de } \\
& \text { refletir normativamente sobre elas } \\
& \text { ou de renovar sua 'ordem', isto é, a } \\
& \text { natureza da coordenação dos } \\
& \text { processos que nelas tem lugar, é } \\
& \text { virtualmente impedida por força de } \\
& \text { sua própria futilidade, donde sua } \\
& \text { inadequação essencial. }
\end{aligned}
$$

Em termos mais simples: não havia possibilidade para o pensamento crítico dos sujeitos frente à sociedade na qual estavam inseridos, por falta de significantes próprios que os permitissem desalienarem-se do poder de controle social vigente, como a Igreja e o Estado. A individualidade e o pensamento per si, 
quando existia, eram suprimidos em virtude da coletividade e da unificação dos desiguais enquanto sociedade culturalmente estabelecida.

Nesse caminhar para a modernidade, naquilo que Bauman chama de "marcas do nosso tempo" (2001, p. 36), se tornou cada vez mais evidente a "mudança na disposição do público, a diminuição do apetite pela reforma social, do interesse pelo bem comum e pelas imagens da boa sociedade, a decadência da popularidade do engajamento político ou a alta dos sentimentos hedonísticos e do 'eu primeiro"” (2001, p. 36).

Assim, nesse processo do apagamento do eu da sociedade sólida para a solitude do eu da sociedade líquida, algumas instituições sociais faliram e outras se modificaram, tomando para si a qualidade de líquidas, tais quais, dentre tantas, a família.

Esse declínio da família como instituição é impossível de ser situado como produto de um fenômeno único, visto que as famílias são rabiscos de ensaio da sociedade as quais pertencem, fornecendo amostras mais ou menos condizentes com o meio social. Com isto, as famílias modernas estão cada vez menores, autocentradas na figura do casal e dos filhos, que modificam a nomenclatura do homem e da mulher de “casal” para par parental, pais.

Esses pais, que têm cada vez menos filhos, tendem a assumir um posicionamento equiparado, no qual o homem não é mais majoritariamente o arrimo da família, e a mulher não é mais somente e forçosamente a cuidadora dos filhos e do lar. Estas mulheres e homens estão cada vez mais inseridos e absorvidos pelo mercado de trabalho, o que faz com que a responsabilidade de criação e mesmo de educação da prole seja delegada a um outro. Nas palavras de Ulrich Beck (1999, citado por Bauman, 2001, p. 13):

Pergunte-se o que é realmente uma família hoje em dia? $\mathrm{O}$ que significa? É claro que há crianças, meus filhos, nossos filhos. Mas, mesmo a paternidade e a maternidade, o núcleo da vida familiar, estão começando a se desintegrar no divórcio... Avós e avôs são incluídos e excluídos sem meios de participar nas decisões de seus filhos e filhas. Do ponto de vista de seus netos, o significado das avós e dos avôs tem que ser determinado por decisões e escolhas individuais. 
Percebamos, então, e não com surpresa, que, já em 1999, havia a problematização da função social da família e dos papeis desempenhados como semblantes, e, não somente destes, mas dos laços sociais mais densos, de um modo geral, cuja dissolução ou fragilização são consideradas como um "efeito colateral" não previsto da nossa fluidez do tempo, do espaço e do poder: "Qualquer rede densa de laços sociais, e em particular uma que esteja territorialmente enraizada, é um obstáculo a ser eliminado" (Bauman, 2001, p. 23).

É sobre este declínio e dissolução das redes sociais fixas e mais ou menos estáveis de outrora, que Tironi (2010, p. 6) fala sobre a "falência dos universais", a despeito da síncope da figura paterna, cuja imagem, desde Freud até a segunda clínica de Lacan, se reduziu de um significante universal e primordial, a uma simples metáfora, que nem sequer chega a ser generalizável, pois se: “O pai em Freud entra como pênis através das diferenças sexuais, da diferença anatômica; . . . em Lacan, o pai entra como Nome, como quem dispõe do significante fálico" (Derzi \& Marcos, 2016, p. 53).

Isso significa dizer que aquilo que era da ordem do universal, do comum a todos, não mais o é. A contemporaneidade significa, então, nas palavras de Rômulo Ferreira da Silva (Brodsky, 2011, p. 99), uma "foraclusão generalizada"; um desbussolamento do sujeito, que, diferente do estruturalismo, diz de um sujeito que não contaria, a priori, com um significante mestre (S1) universal; o que consiste dizer que todos somos, essencialmente, desorientados, faltosos, delirantes. É a passagem "do Um ao múltiplo" (Tironi, 2010, p. 7).

Segundo Brodsky (2011, p. 81), é “Apenas o 'nó de quatro' do Seminário 23 [que] abre as vias para pensarmos a foraclusão generalizada e o parentesco entre os sintomas contemporâneos e a psicose ordinária", sendo possível "extrair, assim, as consequências do declínio do Nome-do-pai na clínica e nos sintomas contemporâneos” (Brodsky, 2011, p. 13), uma vez que, agora, sendo cada sinthoma o mais singular de cada caso, se torna inviável reduzi-lo a apenas um nome entre tantos nomes (Brodsky, 2011, p. 83), referindo-se ao Nome-do-pai na segunda clínica de Lacan.

Mas o que quer dizer essa síncope do Nome-do-Pai nos sujeitos contemporâneos? Segundo Tironi (2010, p. 7), a modificação da clínica das psicoses na modernidade se dá em virtude "do declínio da função paterna e da elevação 
do 'objeto a' ao zênite social, ou seja, do predomínio do objeto sobre o ideal", numa promoção da função do mais-de-gozar.

O que na primeira clínica de Lacan fundava a ordem dos três registros - o Nome-do-Pai -vem, posteriormente, não como aquilo que significa algo, mas antes, como aquilo que amarra os três registros, substituindo o Nome-do-Pai pelo objeto a, que por sua vez, constitui uma falta de representação, um buraco no saber (Derzi \& Marcos, 2016).

Esse mais-de-gozar da atualidade, era controlado, na antiguidade, pela solidez a que Bauman se refere, pois havia um ponto no horizonte sobre o qual se orientar. Uma vez que esse horizonte se mostra débil e frágil, bem como ampliado, os sujeitos se perdem na infinidade daquilo que podem eleger como ponto de referência. Nas palavras de Tironi (2010, p. 7):

No século passado, os ideais funcionavam como moderadores do modo de gozar de determinada cultura. Neste século eles já não predominam nas organizações sociais - o que é diferente de dizer que eles tenham desaparecido -, pois o objeto a está cada vez mais em evidencia. No lugar do ideal que temperava o gozo, houve uma multiplicidade de ideais distintos que não produzem identificações subjetivas que não sejam débeis.

Sobre isto, Bauman (2001, p. 40) diz que não nos moveremos mais em virtude do "adiamento da satisfação", mas, agora há uma impossibilidade de atingi-la, e, consecutivamente, disto resulta e significa ter "uma identidade que só pode existir como projeto não realizado" (Bauman, 2001, p. 41).

Esse declínio da figura paterna e, consequentemente, da inscrição do Nomedo-Pai nos sujeitos, promove uma necessidade de buscar fora aquilo que vai dizer do desejo deste. É com a falta disso que dava base ao enodamento dos três registros na primeira clínica de Lacan, que, na segunda clínica, vem como apenas mais um dos sinthomas, que é o Nome-do-Pai. Nas palavras de Dessal (Bauman \& Dessal, 2017, p. 10):
Acreditei perceber uma ressonância entre o conceito de 'liquidez' e a previsão que Jacques Lacan aventou como consequência da queda da 'imago paterna', figura do discurso que, para além das críticas ou de seus desacertos, cumpriu a 
função de organizar e formalizar as peças soltas da maquinaria humana.

Com isto, entende-se que a liquidez da civilização permite formas alternativas ao ser (ao sujeito) de ser (de se fazer sujeito). Não se trata, embora a utilização dos termos "declínio" ou "falência" possa denotar, de um desaparecimento completo da Lei traduzida na figura paterna como metáfora; pelo contrário, não se trata de uma zerificação absoluta deste pai $\left(\mathrm{NP}_{0}\right)$, mas, antes, de uma pluralização deste referencial, que agora não mais reside na figura de um único Outro, mas que pode estar presente em múltiplas possibilidades. É justamente essa multiplicidade ali onde havia apenas Um, que gera o desbussolamento do sujeito, que, diante de tantas ofertas, fica sem referencial. Neste aspecto, para quem não sabe aonde ir, qualquer caminho pode servir: "O que atormenta os jovens dos nossos dias já não é o excesso de restrições e proibições insidiosas, temíveis e muito reais, mas a preocupante e vasta expansão das opções aparentemente abertas pela dádiva da liberdade consumista" (Bauman \& Dessal, 2017, p. 38).

É então, retomando, através desta frouxa estrutura familiar, já citada, com o par parental cada vez menos presente (não só fisicamente) "em virtude" da liquidez do tempo, que o sujeito se vê às voltas com suas próprias questões, sendo cada vez mais convocado a criar para si e em si uma oportunidade de fazer laço social, numa sugestão de que não nascemos mais com nossa identidade, nos sendo compulsória e obrigatória a necessidade de tornarmo-nos o que "já somos". Nas palavras de Bauman (2001, p. 44): “'individualização' consiste em transformar a 'identidade' humana de um 'dado' em uma 'tarefa' e encarregar os atores da responsabilidade de realizar essa tarefa e das consequências (assim como dos efeitos colaterais) de sua realização".

Em função da já sabida identificação imaginária com o Outro, característico da psicose, tanto extraordinária quanto ordinária, o sujeito se identifica a Outros, seus semelhantes, aqueles com quais não há borda que os separe, portanto, seu duplo especular. Contudo, desta relação, que pode se sustentar ou não ao longo do tempo, algo disso pode se fragilizar em virtude deste Outro que, eventualmente, não sustentará o semblante sob o qual o sujeito psicótico lhe elegeu como grande Outro, convocando o sujeito psicótico a lidar com o Real da realidade e arranjar, para si, uma suplência que ponha seu tamborete novamente em equilíbrio. De acordo com 
Tironi (2010, p. 5): "Éric Laurent chama as psicoses ordinárias de 'psicoses na época da democracia', pois neste tempo cada um tem a possibilidade de apresentar seu estilo pessoal e de tratamento do gozo na estrutura psicótica".

Nas palavras de Beck (1995, p. 40, citado por Bauman, 2001, p. 51):

O que emerge no lugar das normas sociais evanescente é o ego nu, atemorizado e agressivo à procura de amor e de ajuda. Na procura de si mesmo e de uma sociabilidade afetuosa, ele facilmente se perde na selva do eu... Alguém que tateia na bruma de seu próprio eu não é mais capaz de perceber que esse isolamento, esse 'confinamento solitário do ego', é uma sentença de massa.

A partir do momento que o sujeito para no primeiro tempo do Édipo lacaniano, e, portanto, não submete seu gozo ao Outro, haverá um mais-de-gozar permanente desse sujeito, que andará com o objeto a no bolso, servindo-se dele ao seu bel prazer. Em outras palavras: essa não separação entre o sujeito e o Outro, que parece ser mais frequente na modernidade líquida, se dá porque o sintoma se manifesta por duas vias: a singular, que fala sobre o gozo; e a via universal, mediada pelo Outro.

A partir do momento que não há um Outro, então, o sujeito viverá em relação erotomaníaca, donde seu investimento libidinal, seu gozo, estará voltado sempre para si, ainda que numa relação especular, pois este Outro nada mais é do que seu duplo, e, portanto, ele mesmo.

Segundo Derzie Marcos (2016, p. 55), o “objeto a seria a bússola da civilização de hoje, e haveria um privilégio do mais de gozar como gozo contemporâneo". Isto significa dizer do desfalecimento também do mundo simbólico, que, cada vez mais frágil e falho no sujeito que não foi barrado (\$), vive uma plenitude desse mais-de-gozar, porém uma plenitude vazia, uma plenitude do não-todo (Derzi \& Marcos, 2016), que antes era preenchida pela sexuação masculina.

Essas novas modalidades de gozo, sobretudo, não excluem as estruturas psíquicas concebidas por Freud. Pelo contrário, para se dizer que algo preenche a categoria de ser "inclassificável” é preciso, sobretudo, que haja alguma categoria para que estes casos sejam delas excluídas por suas especificidades. 
Isto posto, considerando-se as configurações de uma modernidade líquida, pode-se dizer que o declínio da função paterna e a multiplicidade de sinthomas contemporâneos se configuram como uma benesse desta modernidade fluida. Seguindo essa lógica, do consumo e do desbussolamento, fica posta uma questão: serão cada vez mais raras as psicoses extraordinárias em detrimento das ordinárias, e, antes disso, dos inclassificáveis?

É possível dizer, diante dessa questão, que novas estruturas psíquicas podem aparecer com o tempo e conforme os contextos sociais mudem, ou que novas formas de manifestação clínica destas três estruturas podem se desvelar. São dois modos de se observar a mesma questão. De toda forma, desde Miller (Zbrun, 2010), e considerando que a psicose ocorre quando há a estagnação no primeiro tempo do Édipo, há uma assunção de que nossa “condição natural” seria a psicose; sendo a neurose, portanto, o sucesso na constituição de um sintoma que se impõe a essa condição primeira.

\section{Considerações finais}

Com a descoberta das três estruturas psíquicas fundamentais decorrentes das formas de negação dos sujeitos diante do Complexo de Édipo, mais que como um norteador do manejo da transferência, o diagnóstico das estruturas se mostrou como sendo fixo e como sendo aquele do qual o sujeito não poderia sair jamais, uma vez estabelecido: neuróticos seriam unicamente neuróticos, psicóticos sempre psicóticos e perversos sempre perversos.

Contudo, o que se condensou ao longo do percurso da teoria e da própria clínica foi justamente a singularidade de cada sujeito, a sua irrepetibilidade e a particularidade de cada arranjar sintomático dentro do espectro de sua estrutura basal. Se antes em Freud a neurose era nossa condição "normal", sendo a psicose um avesso desta; em Lacan e, principalmente, em Miller, a consideração é justamente oposta: somos todos psicóticos, e quem não o é, obteve algum sucesso no seu enlaçar sintomático que o permite seguir sem desequilíbrios ao longo da vida.

A foraclusão generalizada é, nessa lógica, nossa condição atual e contemporânea, resultado do declínio, do embotamento e do esfumaçamento de diversas certezas e dimensões antes sólidas; hoje, postas à prova e liquefazendo-se com o passar do tempo, 
que também é líquido. As formas de gozo se multiplicaram e seu valor simbólico para o sujeito se estilhaçou; aquilo que era a regra, hoje é mais um dos desvios dos sintomas.

Se o desbussolamento da modernidade é, pois, nossa condição natural, podemos dizer apenas que a solidez da antiguidade não permitia a visualização disto que realmente somos, que o contexto histórico não era o mais ideal e que tudo que víamos eram apenas amostras dos sujeitos que obtiveram sucessos em suas suplências.

São possibilidades que permanecerão sem norte pelo menos pelos próximos séculos, frente às quais os novos psicanalistas poderão olhar em retrospecto e analisar, comparativamente, tal qual fizemos nesta discussão, as especificidades e as digressões de cada período histórico e seus desdobramentos nos sujeitos. Contudo, deixo ainda uma nova pergunta aos que virão: será o destino da sociedade liquida evaporar-se?

\section{Referências}

Bauman, Z. (2001). Modernidade líquida. Rio de Janeiro: Zahar.

Bauman, Z. \& Dessal, G. (2017). O retorno do pêndulo:sobre a psicanálise e o futuro do mundo líquido.Rio de Janeiro: Zahar.

Brodsky, G. (2011). Loucuras discretas: um seminário sobre as chamadas psicoses ordinárias. Belo Horizonte: Scriptum.

Brousse, M-H. (2009). La psychoseordinaire à La lumiére de La théorielacaniennedudiscours. InQuarto , Revue de psychanalysepubliée à Bruxelles (1994-1995).Bruxelles: École de la Cause freudienne. (Originalmente publicado em 19941995).

Correia, T. M. (2010). Casos raros: as psicoses ordinárias na clínica do delírio generalizado. Opção Lacaniana online nova série, 1(1),1$12 . \quad$ Recuperado de $<$ http://www.opcaolacaniana.com.br /pdf/numero_3/Casos_raros.pdf $>$.

Derzi, C. A. M., \& Marcos, C. M. (2016). A atemporalidade das estruturas psíquicas e o inclassificável.Reverso,38(72), 51-58. Recuperado de $<$ http://pepsic.bvsalud.org/scielo.ph $\mathrm{p}$ ?script $=$ sci_arttext\&pid=S010273952016000200007>.

Freud, S. (2010). Obras completas, volume 10: Observações psicanalíticas sobre um caso de paranóia relatado em autobiografia: ("O caso Schreber"): artigos sobre técnica e outros textos (1911-1913). São Paulo: Companhia das Letras. (Originalmente publicado em 1911-1913).

Freud, S. (2011). "Autobiografia". In S. Freud, Obras completas, volume 16: $O$ eu e o id, "autobiografia" e outros textos (1923-1925). (P. C. Souza, Trad., pp. 75-167). São Paulo: 
Companhia das Letras. (Originalmente publicado em 1925).

Freud, S. (2012). Totem e tabu (191213). In S. Freud, Obras completas, volume 11: totem e tabu, contribuição à história do movimento psicanalítico e outros textos (1912-1914). (1 ${ }^{\mathrm{a}} \mathrm{ed}, \mathrm{P}$. C. Souza, Trad., pp. 13-244). (Originalmente publicado em 19121913).

Freud, S; \& Breuer, J. (2016). Obras completas, volume 2: Estudos sobre a histeria (1893-1895). (1 ${ }^{\mathrm{a}} \quad$ ed., L. Barreto, Trad.), São Paulo: Companhia das Letras. (Originalmente publicado em 1893-1895)

Freud, S. (1976). Sobre a psicoterapia. In. S. Freud, Edição Standard brasileira das obras psicológicas completas de Sigmund Freud, Vol. 7.Rio de Janeiro: Imago. (Originalmente publicado em 1905).

Julien, P. (2003). Psicose, perversão $e$ neurose: a leitura de Jacques Lacan. Rio de Janeiro: Companhia de Freud.

Lacan, J. (1985). O Seminário, livro 3: As psicoses. Rio de Janeiro: Zahar. (Originalmente publicado em 19551956)

Lacan, J. (1999). A lógica da castração. In J. Lacan, $O$ seminário, livro 5: as formações do inconsciente (1957 1958). (V. Ribeiro, Trad., pp. 149257). Rio de Janeiro: Zahar, 1999. (Originalmente publicado em 19571958).

Miller, J-A. (2001). La categoria de semblante. In: De La naturaleza de los semblantes (1992).Buenos Aires: Paidós. (Originalmente publicado em 1992).
Miller, J-A. (2005). Los inclasificables de la clínica psicoanalítica.Buenos Aires: Paidós.

Quinet, A. (1991). As funções das entrevistas preliminares. In A. Quinet, As 4+1 condições da análise. (pp. 13-34). Rio de Janeiro: Zahar.

Riolfi, C. (2014). Quando está indicado o divã: a analise lacaniana tem contraindicações?In J. Forbes, Psicanálise: a clínica do Real. (pp. 37-53). Barueri, SP: Manole.

Tironi, A. C. (2010). A psicose ordinária e os inclassificáveis das categorias lacanianas. Opção Lacaniana Online nova série, 1(1),1-11. Recuperado de<http://www.opcaolacaniana.com.br /pdf/numero_1/Psicose_ordinaria.pdf $>$

Zbrun, M. (2010). A clínica diferencial das psicoses e as psicoses ordinárias.Opção Lacaniana Online,1(3),1-9. Recuperado de $<$ http://www.opcaolacaniana.com.br /pdf/numero_3/A_clinica_diferencial das_psicoses_psicose_ordinaria.pdf $>$.

Talita Noronha Alves é bacharel em Psicologia pela Universidade Estadual da Paraíba (UEPB), mestranda no Programa de Pós Graduação em Psicologia da Saúde (PPGPS) pela Universidade Estadual da Paraíba (UEPB) e pós graduanda em Psicanálise pela Faculdade Integrada de Patos (FIP).

E-mail: tallitanoronha@gmail.com

ORCID: http://orcid.org/0000-0001-8190$\underline{6506}$

Juliana Fonsêca de Almeida Gama possui bacharelado e licenciatura em Psicologia pela Universidade Estadual da 
Paraíba (UEPB) e licenciatura em Letras pela Universidade Federal de Campina Grande (UFCG). É também mestre em Psicologia pela Universidade Federal de Pernambuco (UFPE) e afiliada ao departamento de Psicologia da Universidade Católica de Pernambuco (UNICAP) no Programa de Pós-Graduação em Psicologia Clínica.

E-mail: julianafgama@gmail.com

ORCID: http://orcid.org/0000-0002-2735$\underline{3696}$

Submissão: $24 / 06 / 2020$

$1^{\circ}$ avaliação: $17 / 08 / 2020$

Aceite: $21 / 10 / 2020$ 